\title{
Article \\ Design and Fabrication of a Printed Tri-Band Antenna for 5G Applications Operating across Ka-, and V-Band Spectrums
}

\author{
Musa Hussain ${ }^{1}\left(\mathbb{D}\right.$, Syed Muhammad Rizvi Jarchavi ${ }^{2}$, Syeda Iffat Naqvi ${ }^{3, *} \mathbb{C}$, Usama Gulzar ${ }^{4}$, \\ Salahuddin Khan ${ }^{5}$, Mohammad Alibakhshikenari ${ }^{6, *}{ }^{-1}$ and Isabelle Huynen ${ }^{7}$ (D) \\ 1 Department of Electrical Engineering, Bahria University Islamabad Campus, Islamabad 44000, Pakistan; \\ hussainmusa732@gmail.com \\ 2 Department of Electrical Engineering, Beijing Jiaotong University, Beijing 100044, China; \\ asad_syed113@hotmail.com \\ 3 Telecommunication Engineering Department, University of Engineering Technology, Taxila 47050, Pakistan \\ 4 Department of Electronics Engineering, University of Engineering and Technology, Taxila 47050, Pakistan; \\ usamagul898@gmail.com \\ 5 Electrical Engineering Department, College of Engineering, King Saud University, \\ Riyadh 11421, Saudi Arabia; drskhan@ksu.edu.sa \\ 6 Department of Signal Theory and Communications, Universidad Carlos III de Madrid, \\ 28911 Leganés, Madrid, Spain \\ 7 Institute of Information and Communication Technologies, Electronics and Applied Mathematics, \\ Université Catholique de Louvain, 1348 Louvain-la-Neuve, Belgium; isabelle.huynen@uclouvain.be \\ * Correspondence: iffat.naqvi@uettaxila.edu.pk (S.I.N.); mohammad.alibakhshikenari@uc3m.es (M.A.)
}

check for updates

Citation: Hussain, M.; Jarchavi, S.M.R.; Naqvi, S.I.; Gulzar, U.; Khan, S.; Alibakhshikenari, M.; Huynen, I. Design and Fabrication of a Printed Tri-Band Antenna for 5G Applications Operating across $\mathrm{Ka}$-, and V-Band Spectrums. Electronics 2021, 10, 2674. https://doi.org/10.3390/

electronics10212674

Academic Editor: Sotirios K. Goudos

Received: 26 September 2021

Accepted: 29 October 2021

Published: 31 October 2021

Publisher's Note: MDPI stays neutral with regard to jurisdictional claims in published maps and institutional affiliations.

Copyright: (c) 2021 by the authors. Licensee MDPI, Basel, Switzerland. This article is an open access article distributed under the terms and conditions of the Creative Commons Attribution (CC BY) license (https:/ / creativecommons.org/licenses/by/ $4.0 /)$.

\begin{abstract}
In this paper, an umbrella-shaped patch antenna for future millimeter-wave applications for the $5 \mathrm{G}$ frequency band is presented. The proposed antenna resonates at multiple frequency bands, i.e., $28 \mathrm{GHz}, 38 \mathrm{GHz}$, and $55 \mathrm{GHz}$ (V-band) that have been globally allocated for $5 \mathrm{G}$ communications systems. The proposed antenna is designed using Rogers RT/duroid 5870, with a relative permittivity, loss tangent and thickness of $2.33 \mathrm{~mm}, 0.0012 \mathrm{~mm}$ and $0.79 \mathrm{~mm}$, respectively. The antenna has an overall size of $8 \mathrm{~mm} \times 8 \mathrm{~mm}$ which correspond to $0.7 \lambda \times 0.7 \lambda$, where $\lambda$ is free space wavelength at the lowest resonance. Moreover, the wide bandwidth, high gain and tri band operational mode is achieved by introducing two stubs to the initial design. The antenna prototype was fabricated and validated experimentally. The comparison of the simulated and measured results demonstrates a good correlation. Additionally, the comparative analysis with state of the art work demonstrates that the proposed antenna offers compact size, simple geometrical configuration, wide bandwidth, high gain, and radiation efficiency which makes the proposed antenna a potential candidate for compact smart 5G devices.
\end{abstract}

Keywords: tri-band antenna; millimeter-wave; 5G; V-band

\section{Introduction}

The future generation communication systems demand the high data rate, low cost, efficient, and less complex approaches to handle the exponential increase in the number of users [1]. Thus, the fifth generation (5G) of communication technology has become a promising candidate for the said systems [2,3]. The $28 \mathrm{GHz}$ and $38 \mathrm{GHz}$ are the potential frequency bands for the $5 \mathrm{G}$ cellular communication at millimeter wave (mm-wave) part of spectrum owing to the advantages of low absorption rate and low error for both Line-ofSight (LoS) and Non-Line-of-Sight (NLoS) systems [4,5]. Additionally, V-band (60 GHz) is considered a desirable frequency band for satellite communication systems along with WiFi [6]. Being a key component of the communication system, an antenna operating at 5G mm-wave frequencies must possess a simple geometrical structure along with compact size [7]. However, with increase in compactness due to higher operating frequencies, the fabrication complexity also rises. Furthermore, due to elevated atmospheric absorptions 
and attenuations, 5G antennas necessitate high gain and efficiency for effective transmission $[8,9]$. Though, with small size it becomes challenging for the 5G antenna to attain high gain. Thus, an antenna showing good radiation characteristics is necessary for $28 \mathrm{GHz}$, $38 \mathrm{GHz}$, and $60 \mathrm{GHz}$ mm-wave frequency bands.

Recently, several studies have been conducted regarding single, dual, or multi band operation over mm-wave frequencies [10-19]. The work in [10] proposed a circularly polarized wire-bond antenna for V-band applications with compact size of $2.2 \mathrm{~mm} \times 2.2 \mathrm{~mm}$ along with single wideband ranging from $51 \mathrm{GHz}$ to $67 \mathrm{GHz}$. However, the design has complex geometrical configuration and low gain of $-0.8 \mathrm{dBi}$. Similarly, another antenna for V-band mm-wave applications is presented in [11]. This antenna attained wide bandwidth ranging from $57 \mathrm{GHz}$ to $66 \mathrm{GHz}$ and a high gain value of $14 \mathrm{dBi}$. Conversely, the antenna has larger dimensions with increased fabrication complexity. The antenna design reported in [12] is a mm-wave microstrip-fed antenna, where a single resonating band is obtained between $34.1 \mathrm{GHz}$ and $38.9 \mathrm{GHz}$. The reported structure attained directivity values ranging between $6 \mathrm{dBi}$ and $8 \mathrm{dBi}$ for single antenna configuration and with parasitic patches, respectively. In another work [13], a tri-band antenna is proposed for 5G mm-wave applications. The proposed structure is a stacked configuration with microstrip feed on one layer and proximity coupled parasitic patches on the second layer. This antenna resonates at $45.3 \mathrm{GHz}, 57 \mathrm{GHz}$, and $66 \mathrm{GHz}$ frequency ranges with peak gain of $5.66 \mathrm{dBi}$. Likewise, a triple band antenna with comparatively simple structure is presented in [14] for mm-wave communication systems. This antenna obtained peak gain of $6.5 \mathrm{dBi}, 7 \mathrm{dBi}$, and $5 \mathrm{dBi}$ at resonant frequencies of $24 \mathrm{GHz}, 28 \mathrm{GHz}$, and $38 \mathrm{GHz}$, respectively, with relatively narrow impedance bandwidths. Another triple band slotted mm-wave antenna with inset feed and resonating at $27 \mathrm{GHz}, 35 \mathrm{GHz}$, and $54 \mathrm{GHz}$ is reported [15]. The peak gain attained by the antenna over the resonating bands is $6.3 \mathrm{dBi}$. Another study [16] proposed a mm-wave antenna with dual band operation for $28 \mathrm{GHz}$ and $38 \mathrm{GHz} 5 \mathrm{G}$ communication systems. The proposed antenna covers the 26.65-29.2 GHz and 36.95-39.05 GHz bands, whereas the peak gain values of $1.27 \mathrm{dBi}$ and $1.83 \mathrm{dBi}$ are attained for the two resonant frequencies, respectively. Additionally, the antenna design reported in [17] is a high gain dual band antenna operating at $28 \mathrm{GHz}$ and $38 \mathrm{GHz}$. However, the antenna has large substrate dimensions. The antenna design presented in [18] is a T-shaped dual band antenna operational at 28/38 GHz 5G mm-wave frequencies, whereas a triangular shaped slot is also incorporated at the bottom layer for antenna performance enhancement. A peak gain of $5.75 \mathrm{dBi}$ and $7.23 \mathrm{dBi}$ is observed at 28 and $38 \mathrm{GHz}$, respectively. Another triangular patch multiband antenna is reported for both microwave and mm-wave frequency applications [19]. This antenna covers the $23-28 \mathrm{GHz}$ mm-wave band with peak gain value of $5.85 \mathrm{~dB}$ at $26 \mathrm{GHz}$, however the overall size of the proposed structure is comparatively large. From this discussion it is clear that designing a low profile [20] and compact antenna with wide bandwidth, high gain and multiband characteristics at mm-wave frequencies is a real challenge for researchers.

Considering the afore mentioned challenges and the limitations in the earlier reported works, a geometrically simple, compact, low-profile, wideband, high gain and multiband patch antenna for $28 \mathrm{GHz}, 38 \mathrm{GHz}$, and $55 \mathrm{GHz}$ mm-wave applications is presented in this paper. Considering the several benefits of patch antennas [21], i.e., compact sizes, low profiles and simple geometries, etc., this work focused on a patch antenna when designing the desired antenna. The good radiation and multiband characteristics ascertain the suitability of the proposed antenna for mm-wave communication devices. The remaining paper is organized as follows: Section 2 presents the design methodology of the proposed multiband antenna, along with design stages and parametric analysis. In Section 3 the effective parameters of antenna are analyzed and discussed. Section 4 provides the comparative analysis with state of the art works. Section 5 concludes the work accompanied by references. 


\section{Antenna Design Methodology}

\subsection{Antenna Geometery}

Figure $1 \mathrm{a}-\mathrm{c}$ presents the top, back, and side views of the proposed antenna. The antenna design is modeled using Rogers RT/Duroid 5870 with a relative permittivity of 2.33, a loss tangent of 0.0012 and a thickness of $0.79 \mathrm{~mm}$. The overall substrate dimensions are $\mathrm{L}_{1} \times \mathrm{W}_{1} \times \mathrm{H}$. The antenna geometry consists of a semicircular radiator etched at the top side of the substrate and is designed using copper according to a 113-standard thickness $(0.035 \mathrm{~mm})$ with an effective length of $\lambda / 2$, which is fed using a microstrip line. The final proposed design consists of a semicircular patch antenna with a rectangular stub loaded at the bottom along with two triangular protrusions at the corners of the patch, as illustrated in Figure 1a, whereas the back side of the substrate contains a full ground plane. The simulations of the proposed antenna were performed using a Higher Frequency Structural Simulator (HFSS). In order to achieve the optimal radiation characteristics, various parameters of the antenna were optimized in each design step. The optimized dimensions of the proposed tri-band antenna are as follows: $\mathrm{W}_{1}=8 \mathrm{~mm}, \mathrm{~L}_{1}=8 \mathrm{~mm}, \mathrm{H}=0.79 \mathrm{~mm}, \mathrm{~L}_{3}=0.8 \mathrm{~mm}$, $\mathrm{W}_{3}=3.26 \mathrm{~mm}, \mathrm{~L}_{2}=1.4 \mathrm{~mm}, \mathrm{~W}_{2}=0.7 \mathrm{~mm}, \mathrm{~L}_{4}=0.5 \mathrm{~mm}, \mathrm{~W}_{4}=1 \mathrm{~mm}, \mathrm{R}=2.5 \mathrm{~mm}$. The resultant antenna exhibits triband behavior showing resonances at $28 \mathrm{GHz}, 38 \mathrm{GHz}$, and $54 \mathrm{GHz}$.

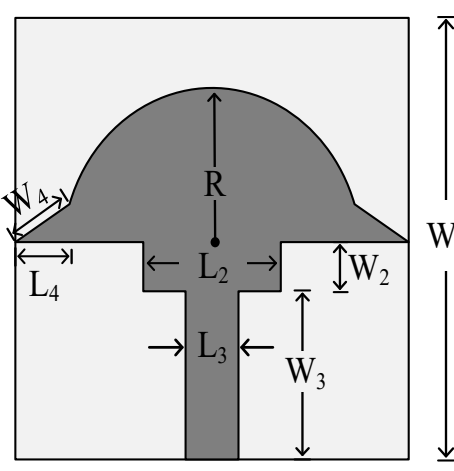

(a)

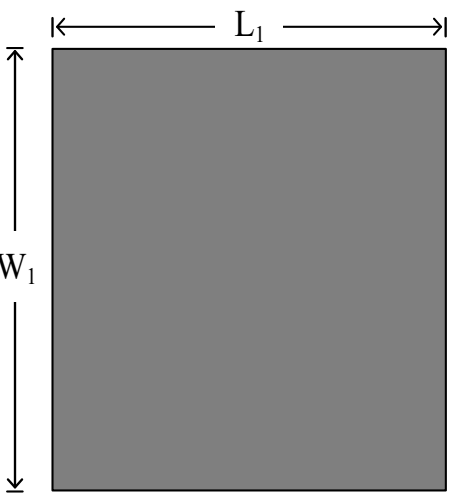

(b)

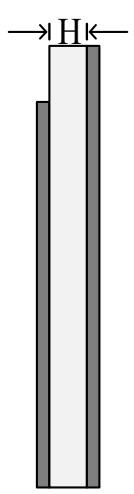

(c)

Figure 1. The geometry of the proposed antenna consists of a microstrip feedline and umbrellashaped patch (a) top view (b) bottom view (c) side view.

\subsection{Antenna Design Stages}

The final optimized antenna design is obtained in four major steps illustrated in Figure 2. Initially, a circular patch antenna was obtained resonating at a higher frequency of $44 \mathrm{GHz}$. The circular patch antenna is designed by using well known equations from [22].

The circular patch antenna resonates around $44 \mathrm{GHz}$ with an impedance bandwidth of $43-45 \mathrm{GHz}$, as exhibited by the reflection coefficient results in Figure 2. In the next step, two identical rectangular slots are etched from the circular radiator resulting in the formation of a semi-circular-shaped radiator. This modification results in widening of the band with bandwidth ranging from $40 \mathrm{GHz}$ to $54 \mathrm{GHz}$, whereas another band at $30 \mathrm{GHz}$ is also obtained at this step, as depicted in Figure 2. Although two resonant bands were obtained in this step, the band at lower frequency is somewhat narrow and does cover the desired frequency band for $5 \mathrm{G}$ communication. In order to obtain the targeted bands, a rectangular shaped stub is loaded at the bottom of semi-circular shaped radiator. The stub loading technique is well known due to its numerous advantages, not limited to improvement of the impedance bandwidth and improved matching at the desired frequency, as explained briefly in [23-25]. The stub loaded semi-circular radiator offers tri band operational modes with pass bands of $29.7-33 \mathrm{GHz}, 38-40.5 \mathrm{GHz}$ and $52-58 \mathrm{GHz}$ with respective resonances at $30 \mathrm{GHz}, 39 \mathrm{GHz}$, and $54 \mathrm{GHz}$. Later, optimization is carried out to shift the resonating frequencies towards targeted band spectrums. Through parametric analysis, two triangular shaped protrusions are incorporated at the corners of the semicircular patch to achieve the 
aforementioned goal. Consequently, three resonances at 28,38 , and $55 \mathrm{GHz}$ are obtained as shown in Figure 2.
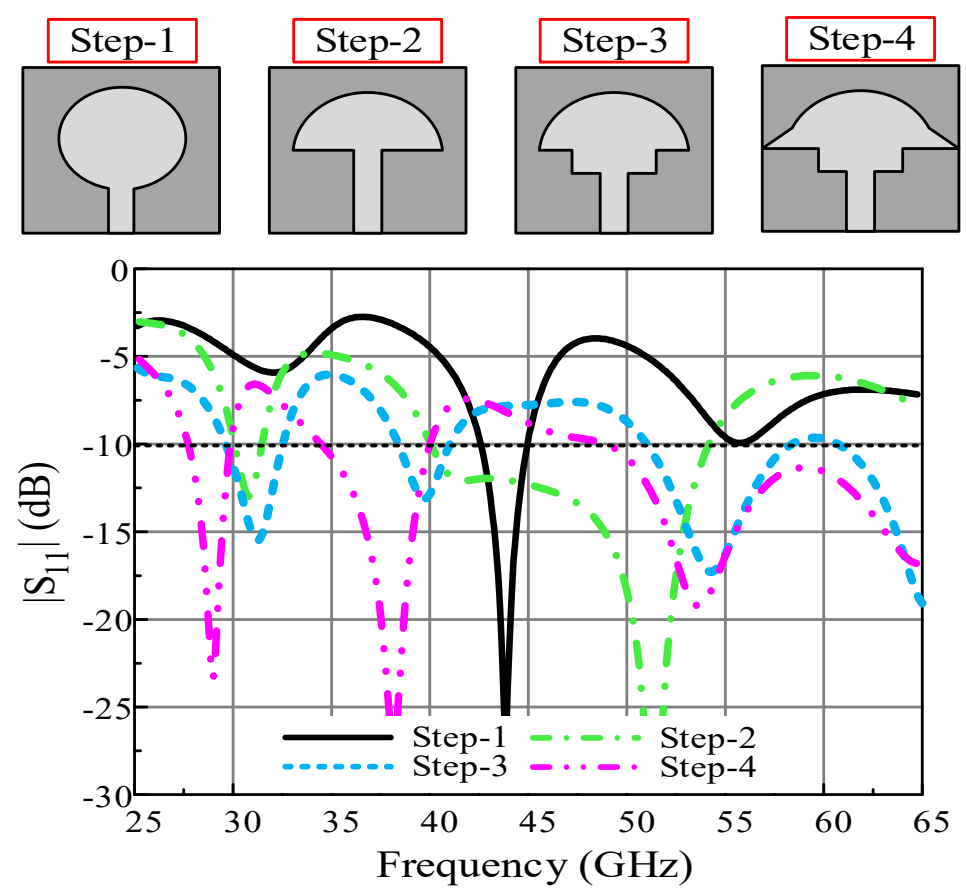

Figure 2. Comparison of return losses of different stages of design of the proposed antenna.

\subsection{Parameteric Analysis}

To obtain the desired frequency bands with wide bandwidth and to improve the impedance matching, parametric analysis of important parameters is performed. The length $\left(\mathrm{L}_{2}\right)$ and width $\left(\mathrm{W}_{2}\right)$ of the stub plays a significant role in designing the antenna in order to achieve the required resonance frequencies along with the wide band and higher impedance matching. If the length of the rectangular stub is set at $1.6 \mathrm{~mm}$, it attains a narrow V-band ranging from $52 \mathrm{GHz}$ to $58 \mathrm{GHz}$. In addition, mismatching and shifting to undesirable frequencies is observed for other two bands, as depicted in Figure 3. If the value of $L_{2}$ is reduced to $1.4 \mathrm{~mm}$, the antenna performance shows significant improvement due to increase in impedance matching at resonant bands as well as widening of the V-band being observed. If $L_{2}$ is further reduced to $1.2 \mathrm{~mm}$, again impedance mismatching and narrowing of the bands occurs. Thus, the optimized value for length of the stub is $1.4 \mathrm{~mm}$, which shows best performance in terms of bandwidth as well as reflection coefficient.

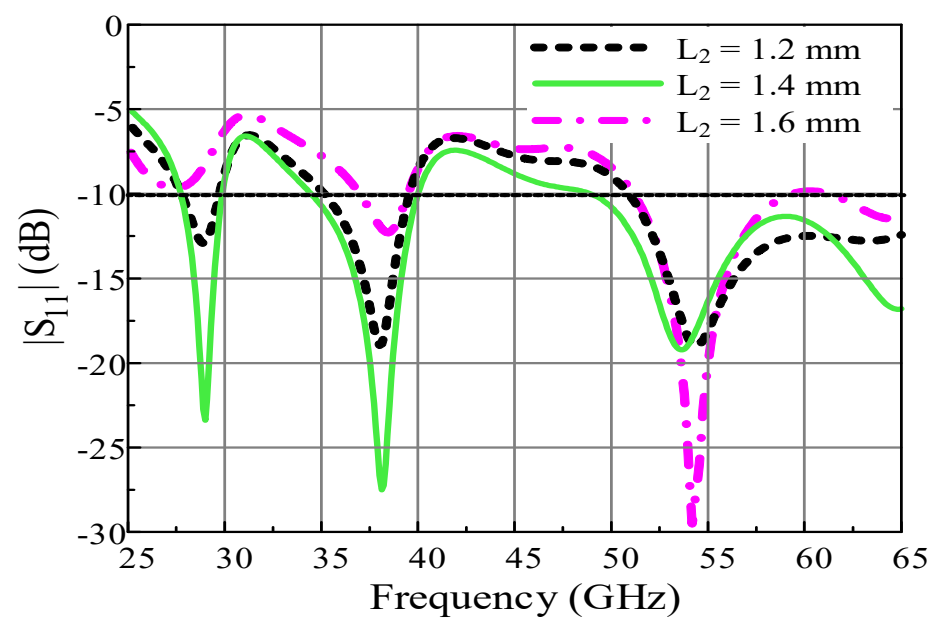

Figure 3. Parametric analysis performed over the length of the rectangular stub $\left(\mathrm{L}_{2}\right)$. 
Figure 4 demonstrates the parametric analysis for the width $\left(\mathrm{W}_{2}\right)$ of the rectangular stub. It is observed from the reflection coefficient curves that at the optimal value of $\mathrm{W}_{2}=0.7 \mathrm{~mm}$, the antenna resonates at $28 \mathrm{GHz}, 38 \mathrm{GHz}$, and $55 \mathrm{GHz}$ frequencies with bandwidth ranging from $27.3 \mathrm{GHz}$ to $29.6 \mathrm{GHz}, 34.8$ to $39.4 \mathrm{GHz}$, and 49.8 to $65 \mathrm{GHz}$. If the value of $W_{2}$ is increased and fixed at $0.9 \mathrm{~mm}$, adverse effects are noticed in terms of impedance mismatch at the $28 \mathrm{GHz}$ and $38 \mathrm{GHz}$ bands, where only two bands are achieved and resonance at the V-band is lost as the band shifts above $-10 \mathrm{~dB}$. As a result, the bandwidth is reduced from $2.3 \mathrm{GHz}, 4.6 \mathrm{GHz}$, and $21.5 \mathrm{GHz}$ to $1 \mathrm{GHz}, 3.5 \mathrm{GHz}$, and $19 \mathrm{GHz}$, respectively, at $28 \mathrm{GHz}, 38 \mathrm{GHz}$, and $55 \mathrm{GHz}$. On the other hand, if $\mathrm{W}_{2}$ is set at $0.5 \mathrm{~mm}$, then again narrowing of the bandwidth as well as impedance mismatch is observed. Therefore, it is concluded that the optimal value for $W_{2}$ is $0.7 \mathrm{~mm}$, which exhibits triband operation with a wide required bandwidth at mm-wave frequencies.

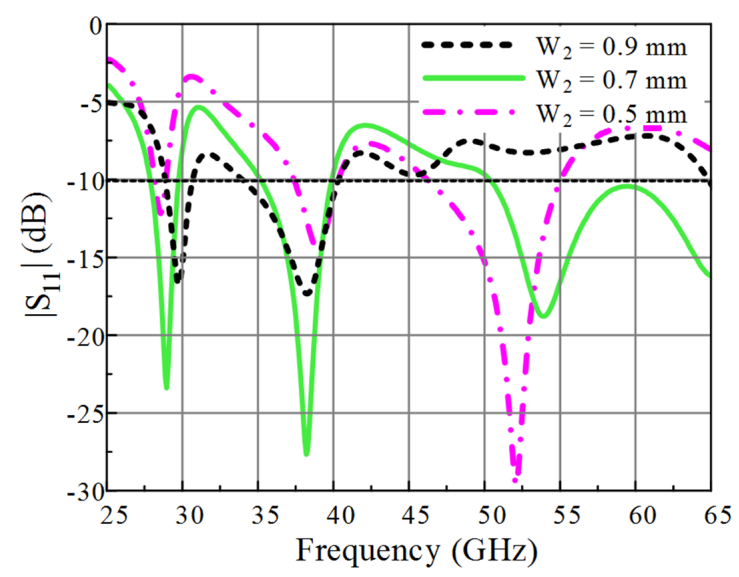

Figure 4. Parametric analysis performed over the width of the rectangular stub $\left(\mathrm{W}_{2}\right)$.

Figure 5 expresses the parametric analysis of thickness of substrate material. It can be observed that, at the optimal value of $\mathrm{H}=0.79 \mathrm{~mm}$, the proposed antenna offers triband at $28 \mathrm{GHz}, 38 \mathrm{GHz}$ and $55 \mathrm{GHz}$. If the thickness of substrate is reduced to $0.5 \mathrm{~mm}$, it has effects on bandwidth as well as impedance matching. The antenna resonates at $30 \mathrm{GHz}$ and $57 \mathrm{GHz}$, with bandwidth the ranging from $29 \mathrm{GHz}$ to $31 \mathrm{GHz}$ and $55 \mathrm{GHz}$ to $65 \mathrm{GHz}$, respectively, as depicted in Figure 5. On other hand, if the thickness of substrate in increased to $1.00 \mathrm{~mm}$, it shifts the obtained band towards the lower side, whereas the V-band is lost. The antenna only resonates for bands from $26 \mathrm{GHz}$ to $30 \mathrm{GHz}$ and $37 \mathrm{GHz}$ to $38 \mathrm{GHz}$ with impedance mismatching, as shown in Figure 5.

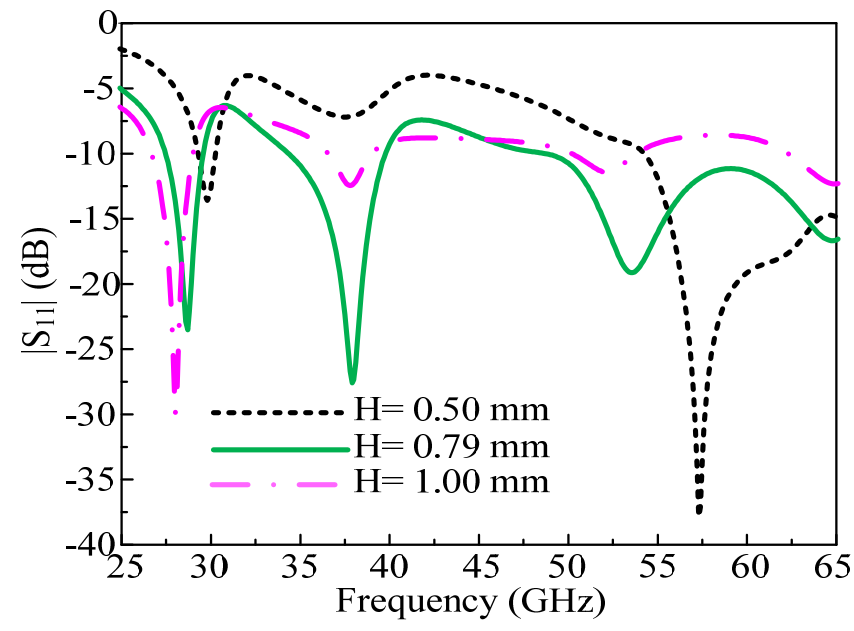

Figure 5. Parametric analysis performed over the thickness of the substrate $(\mathrm{H})$. 


\subsection{Surface Current Distribution}

Figure 6 illustrates the surface current distribution of the proposed antenna at selected resonating frequencies of $28 \mathrm{GHz}, 38 \mathrm{GHz}$, and $54 \mathrm{GHz}$. It can be observed from Figure $6 \mathrm{a}, \mathrm{b}$ that the current distribution is highest along the rectangular stub and the triangular protrusions of the semi-circular radiator, representing the larger effective electrical length which justifies the generation of lower resonances at $28 \mathrm{GHz}$ and $38 \mathrm{GHz}$. Moreover, it can be detected in Figure $6 c$ that, for the selected frequency of $54 \mathrm{GHz}$, the maximum current is distributed along the bottom of the rectangular stub and feedline which represents the small electrical size and controls the generation of higher band at $54 \mathrm{GHz}$.

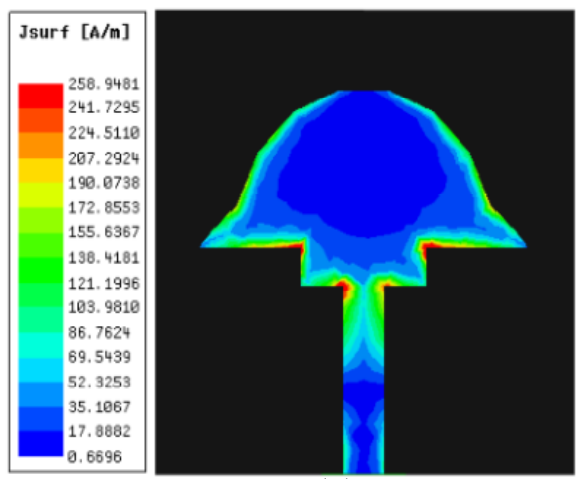

(a)

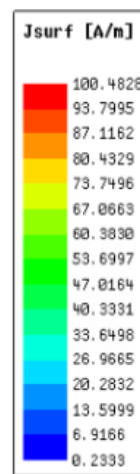

6. 2939

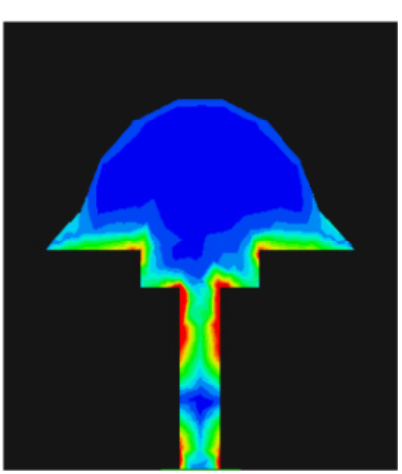

(b)

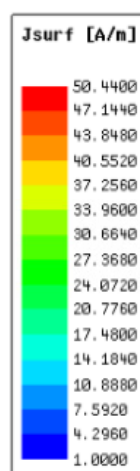

9000

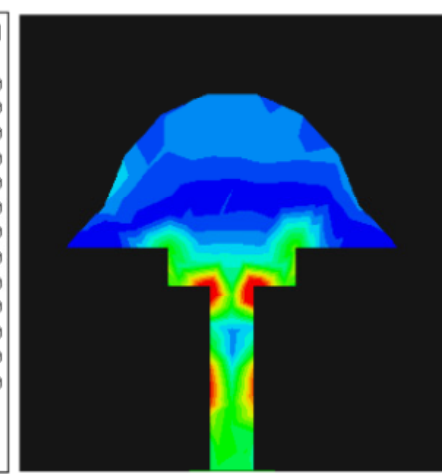

(c)

Figure 6. The surface current distribution of proposed antenna the selected frequencies of (a) $28 \mathrm{GHz}$ (b) $38 \mathrm{GHz}$ (c) $54 \mathrm{GHz}$.

\section{Experimental Results and Discussions}

Analysis of the proposed antenna performance through various performance metrics is provided in this section with detailed comparison of measured and simulated results. For experimental validation, the antenna prototype was fabricated on a ROGERS 5880 substrate as illustrated in Figure 7a, and measured using $1.85 \mathrm{~mm}$ narrow block End Launch Connector by withwave ${ }^{\circledR}$, with a maximum operating frequency of $67 \mathrm{GHz}$ [26].

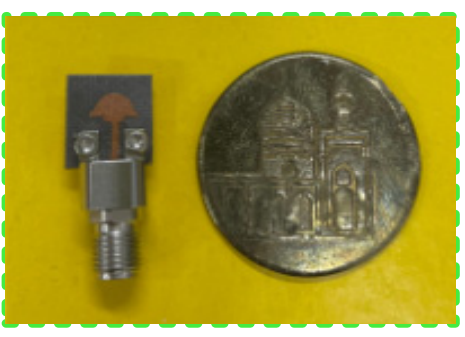

(a)

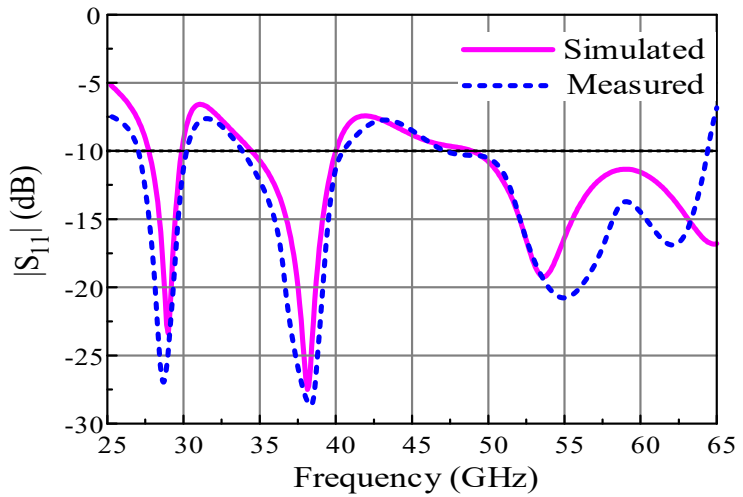

(b)

Figure 7. (a) Hardware prototype of the proposed antenna; (b) comparison of the predicted and measured return losses of the proposed work.

\subsection{Measurement Setup}

The Vector Network Analyzer (VNA) model R\&S ZVA110, which has frequency range up to $110 \mathrm{GHz}$ by Rohde \& Schwarz, was utilized to verify the reflection coefficient to study and verfiy the frequency domain reflection propoerties of proposed tri-band antenna. For far-field measurement, the shielded RF anechoic chamber was used in order to vadilate the far-field radation characteristics of the proposed design. A standrad horn antenna 
(SGH-series) with gain of $24 \mathrm{dBi}$ was used as a transmitter while the proposed antenna was used as a receiver to obtain accurate gain measurements. The signal generated by voltage controlled oscillator (VCO) can be effected by transmission losses and open air. To overcome these effects, high gain power amplifiers were used in the measurement setup as they are able to boost the generated signal and efficient transmission of the radio signal was obtained from the transmitter to the receiver.

\subsection{S-parameters}

The measured and simulated reflection coefficient results of the proposed antenna are demonstrated in Figure 7b. It can be observed that the proposed antenna exhibits triband operational modes with resonances at $28 \mathrm{GHz}, 38 \mathrm{GHz}$, and $54 \mathrm{GHz}$. The impedance bandwidths of the proposed antenna with reference to $\left|S_{11}\right|<-10 \mathrm{~dB}$ can be observed to range from $27.3 \mathrm{GHz}$ to $29.6 \mathrm{GHz}, 34.8 \mathrm{GHz}$ to $40 \mathrm{GHz}$ and $49.8 \mathrm{GHz}$ to $64.8 \mathrm{GHz}$. The proposed antenna shows significant performance covering the whole band spectrums of $28 \mathrm{GHz}$ and $38 \mathrm{GHz}$ allocated by FCC for $5 \mathrm{G} \mathrm{mm-wave} \mathrm{communication,} \mathrm{along} \mathrm{with} \mathrm{the}$ V-band allocated globally. Thus, an overall good agreement between the simulated and measured results can be observed; nevertheless, the insignificant disagreement is due to errors in the fabrication and measurement apparatus.

\subsection{Radiation Pattern}

Figure $8 \mathrm{a}-\mathrm{c}$ depicts the radiation pattern of the proposed antenna at various resonating frequencies. It can be noticed that antenna exhibits broadside radiation pattern at $28 \mathrm{GHz}$ for the $\mathrm{H}$-plane, whereas for the E-plane a slight tilt is observed in the radiation pattern, as shown in Figure $8 \mathrm{a}$. Furthermore, Figure $8 \mathrm{~b}$ illustrates that, for $38 \mathrm{GHz}$, a slightly tilted radiation pattern is obtained in the principle E-plane, while in the H-plane a dual beam radiation pattern is formed at angles of $\pm 30^{\circ}$. For $55 \mathrm{GHz}$, the radiation pattern is directed towards an angle of $-30^{\circ}$ in E-plane; however, for the H-plane the antenna exhibits a dual beam like radiation pattern, as shown in Figure 8c. It can also be observed that simulated and measured results show good correlation.

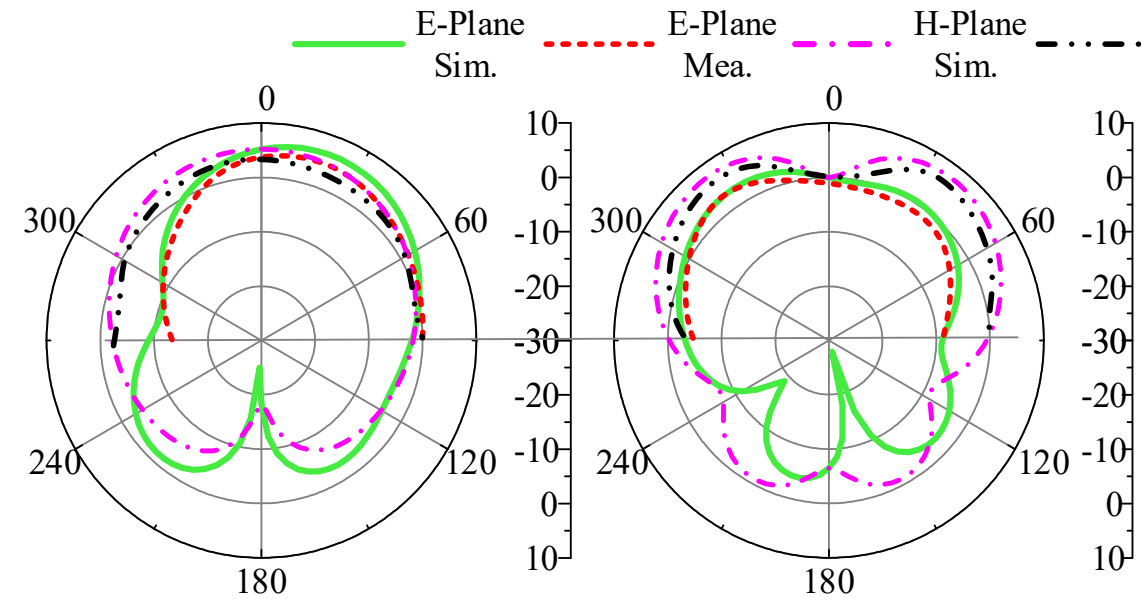

(a)

(b) H-Plane

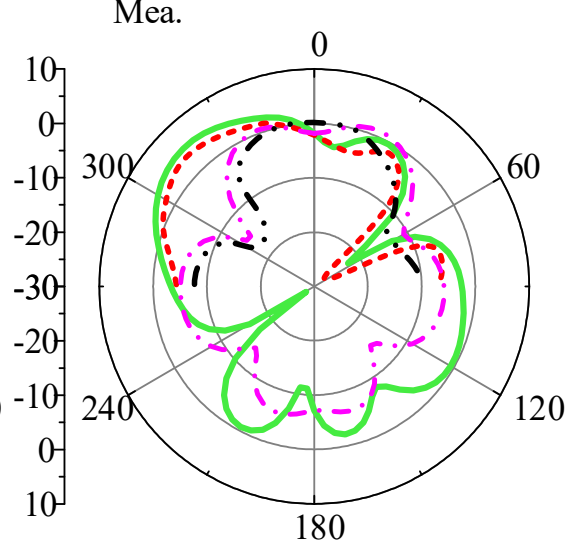

(c)

Figure 8. The gain of the proposed tri-band antenna at (a) $28 \mathrm{GHz}$ (b) $38 \mathrm{GHz}$ (c) $55 \mathrm{GHz}$.

\subsection{Gain and Radiation Efficiency}

The simulated and measured peak gain along with radiation efficiency is illustrated in Figure 9. The simulated values demonstrate that the proposed antenna attains peak gains of $6.8 \mathrm{dBi}, 7.15 \mathrm{dBi}$ and $7.4 \mathrm{dBi}$ at $28 \mathrm{GHz}, 38 \mathrm{GHz}$, and $55 \mathrm{GHz}$, whereas the measured peak gains are $6.6 \mathrm{dBi}, 7.0 \mathrm{dBi}$ and $7.35 \mathrm{dBi}$ at the three resonant frequencies. The radiation efficiency of the proposed antenna can be observed at $>85 \%$ for all resonating bands, as depicted in Figure 9. 


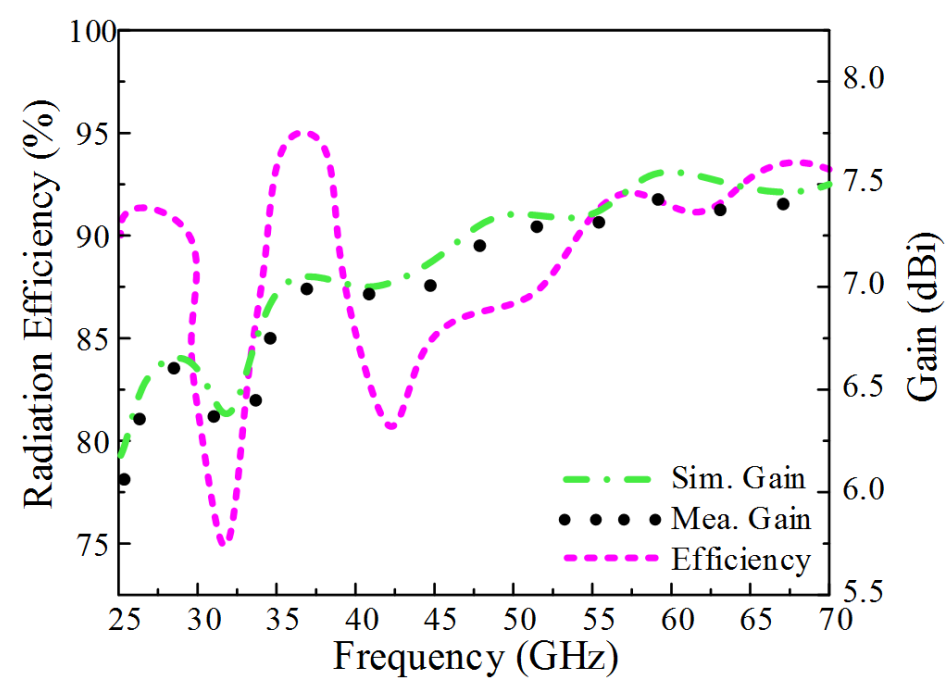

Figure 9. Radiation efficiency and gain curves versus operating frequency bands.

\section{Comparison with State-of-the-Art-Works}

Table 1 presents the comparison of the proposed antenna with the recently reported literary studies. It can be observed that the presented work offers compact-sized antenna as compared to most of the other works. Even though the antennas reported in [13-15] are triband comparatively compact, these antennas exhibit narrow bandwidth and low gain. Additionally, the studies [16-18] reported large-sized antennas with dual band operation and a relatively narrow bandwidth. Thus, good radiation characteristics of the proposed triband antenna such as wide bandwidth, significant antenna gain, better radiation efficiency along with simple and compact structure endorse the suitability of the design for communication devices operating in a $5 \mathrm{G}$ mm-wave spectrum.

Table 1. Comparison of proposed work with related work.

\begin{tabular}{cccccc}
\hline Ref. & $\begin{array}{c}\text { Antenna Size } \\
\left(\mathbf{m m}^{\mathbf{2}} \mathbf{)}\right.\end{array}$ & $\begin{array}{c}\text { Bandwidth } \\
\mathbf{( G H z )}\end{array}$ & $\begin{array}{c}\text { Operational } \\
\text { Mode }\end{array}$ & $\begin{array}{c}\text { Operating } \\
\text { Frequency } \\
\mathbf{( G H z )}\end{array}$ & $\begin{array}{c}\text { Peak Gain } \\
\mathbf{( d B i})\end{array}$ \\
\hline$[13]$ & $10 \times 5 \times 0.51$ & $3,5,3$ & Tri-Band & $45,57,66$ & 5.6 \\
{$[14]$} & $4 \times 5 \times 0.2$ & $0.5,0.9,0.4$ & Tri-Band & $24.4,28,38$ & $6.5,7,5$ \\
{$[15]$} & $8 \times 8 \times 1.6$ & $2.5,1.6,7$ & Tri-Band & $26,35,54$ & $5.8,4.5,6$ \\
{$[16]$} & $14 \times 12 \times 0.38$ & $2.6,2.1$ & Dual Band & 28,38 & $1.27,1.83$ \\
{$[17]$} & $55 \times 110 \times 0.05$ & $0.8,1.5$ & Dual Band & 28,38 & $7.9,8.2$ \\
{$[18]$} & $20 \times 20 \times 1.95$ & $4.8,3.6$ & Dual Band & 28,38 & $5.7,7.2$ \\
This work & $8 \times 8 \times 0.79$ & $2.3,5.2,15$ & Tri-Band & $28,38,55$ & $6.6,7.0,7.35$ \\
\hline
\end{tabular}

\section{Conclusions}

A geometrically simple and compact-sized tri-band antenna is presented in this paper. The geometry of the antenna is composed of a semicircular radiator loaded with a rectangular stub and triangular protrusions to achieve the desired tri-bands at the respective frequencies of $28 \mathrm{GHz}, 38 \mathrm{GHz}$, and $54 \mathrm{GHz}$. The antenna covers the allocated band spectrum for $28 \mathrm{GHz}(27.5-28.25 \mathrm{GHz}), 38 \mathrm{GHz}(36.5-39.25 \mathrm{GHz})$, and V-band (57-64 GHz) while it has a measured high gain of $6.6-7.35 \mathrm{dBi}$, moderately stable radiation patterns, and high radiation efficiency. Moreover, comparative analysis of the proposed antenna with state-of-the-art work demonstrates that the proposed antenna is a potential candidate for future communication systems. 
Author Contributions: Conceptualization, M.H., S.M.R.J., S.I.N., U.G., S.K., M.A. and I.H.; methodology, M.H., S.M.R.J., S.I.N., U.G., M.A. and I.H.; software, M.H., S.M.R.J. and S.I.N.; validation, M.H., S.M.R.J., S.I.N., U.G., S.K., M.A. and I.H.; formal analysis, M.H., S.M.R.J., S.I.N., U.G., M.A. and I.H.; investigation, M.H., S.M.R.J., S.I.N., U.G. and M.A.; re-sources, M.H., S.M.R.J., S.I.N. and U.G.; data curation, M.H., S.M.R.J., S.I.N., U.G., M.A. and I.H.; writing-original draft preparation, M.H. and S.M.R.J.; writing-review and editing, M.H., S.M.R.J., S.I.N., U.G., S.K., M.A. and I.H.; visualization, M.H., S.M.R.J., S.I.N., U.G. and M.A.; supervision, S.I.N.; project administration, S.I.N., U.G., M.A. and I.H.; funding acquisition, S.K. and M.A. All authors have read and agreed to the published version of the manuscript.

Funding: This project received funding from Universidad Carlos III de Madrid and the European Union's Horizon 2020 research and innovation program under the Marie Sklodowska-Curie Grant 801538. Furthermore, this work was partially supported by the Researchers Supporting Project number (RSP-2021/58), King Saud University, Riyadh, Saudi Arabia.

Data Availability Statement: All data are included within the manuscript.

Acknowledgments: The authors appreciate financial support from Universidad Carlos III de Madrid and the European Union's Horizon 2020 research and innovation program under the Marie SklodowskaCurie Grant 801538. Moreover, this work was partially supported by the Antenna and Wireless Propagation Group (https:/ / sites.google.com/view/awpgrp/home, assessed on 15 August 2021) and from the Researchers Supporting Project number (RSP-2021/58), King Saud University, Riyadh, Saudi Arabia.

Conflicts of Interest: The authors declare no conflict of interest.

\section{References}

1. Iqbal, A.; Altaf, A.; Abdullah, M.; Alibakhshikenari, M.; Limiti, E.; Kim, S. Modified U-Shaped Resonator as Decoupling Structure in MIMO Antenna. Electronics 2020, 9, 1321. [CrossRef]

2. Awan, W.; Naqvi, S.; Ali, W.; Hussain, N.; Iqbal, A.; Tran, H.; Alibakhshikenari, M.; Limiti, E. Design and Realization of a Frequency Reconfigurable Antenna with Wide, Dual, and Single-Band Operations for Compact Sized Wireless Applications. Electronics 2021, 10, 1321. [CrossRef]

3. Awan, W.A.; Naqvi, S.I.; Naqvi, A.H.; Abbas, S.M.; Zaidi, A.; Hussain, N. Design and Characterization of Wideband Printed Antenna Based on DGS for 28 GHz 5G Applications. J. Electromagn. Eng. Sci. 2021, 21, 177-183. [CrossRef]

4. Zahra, H.; Awan, W.; Ali, W.; Hussain, N.; Abbas, S.; Mukhopadhyay, S. A 28 GHz Broadband Helical Inspired End-Fire Antenna and Its MIMO Configuration for 5G Pattern Diversity Applications. Electronics 2021, 10, 405. [CrossRef]

5. Das, P.; Mandal, K.; Lalbakhsh, A. Single-layer polarization-insensitive frequency selective surface for beam reconfigurability of monopole antennas. J. Electromagn. Waves Appl. 2020, 34, 86-102. [CrossRef]

6. Hussain, M.; Awan, I.A.; Rizvi, S.M.; Alibakhshikenari, M.; Falcone, F.; Limiti, E. Simple Geometry Multi-Bands Antenna for Millimeter-Wave Applications at $28 \mathrm{GHz}, 38 \mathrm{GHz}$, and $55 \mathrm{GHz}$ Allocated To 5G Systems. In Proceedings of the 46th International Conference on Infrared, Millimeter and Terahertz Waves (IRMMW-THz), Online Conference, 29 August-3 September 2021; pp. 1-2.

7. Hussain, N.; Jeong, M.-J.; Abbas, A.; Kim, T.-J.; Kim, N. A Metasurface-Based Low-Profile Wideband Circularly Polarized Patch Antenna for 5G Millimeter-Wave Systems. IEEE Access 2020, 8, 22127-22135. [CrossRef]

8. Adibi, S.; Honarvar, M.A.; Lalbakhsh, A. Gain Enhancement of Wideband Circularly Polarized UWB Antenna Using FSS. Radio Sci. 2021, 56, e2020RS007098. [CrossRef]

9. Hussain, M.; Rizvi, S.M.; Abbas, A.; Nadeem, A.; Alam, I.; Iftikhar, A. A Wideband Antenna for V-Band Applications in 5G Communications. In Proceedings of the International Bhurban Conference on Applied Sciences and Technologies (IBCAST), Islamabad, Pakistan, 12-16 January 2021; pp. 1017-1019.

10. Lin, T.-Y.; Chiu, T.; Chang, D.-C. Design of V-Band Wide-Beamwidth Circularly Polarized Wire-Bond Antenna. IEEE Trans. Compon. Packag. Manuf. Technol. 2017, 8, 261-268. [CrossRef]

11. Wu, J.; Na Huang, W.; Cheng, Y.J.; Fan, Y. A broadband high-gain planar array antenna for V-band wireless communication. In Proceedings of the 3rd Asia-Pacific Conference on Antennas and Propagation, Harbin, China, 26-29 July 2014 ; pp. 309-312. [CrossRef]

12. Kornprobst, J.; Wang, K.; Hamberger, G.; Eibert, T.F. A mm-Wave Patch Antenna with Broad Bandwidth and a Wide Angular Range. IEEE Trans. Antennas Propag. 2017, 65, 4293-4298. [CrossRef]

13. Firdausi, A.; Hakim, G.; Alaydrus, M. Designing a tri-band microstrip antenna for targetting $5 \mathrm{~g}$ broadband communications. MATEC Web of Conference EDP Sci. 2018, 218, 03015. [CrossRef]

14. Kamal, M.S.; Islam, M.J.; Uddin, M.J.; Imran, A.Z.M. Design of a tri-band microstrip patch antenna for 5G application. In Proceedings of the 2018 International Conference on Computer, Communication, Chemical, Material and Electronic Engineering (IC4ME2), Rajshahi, Bangladesh, 8-9 February 2018; pp. 1-3. 
15. Amrutha, G.M.; Sudha, T. Triple Band Antenna for 5G Applications. In Proceedings of the 2018 International Conference on Advances in Computing, Communications and Informatics (ICACCI), Bangalore, India, 19-22 September 2018; pp. 1650-1652.

16. Hasan, N.; Bashir, S.; Chu, S. Dual band omnidirectional millimeter wave antenna for 5G communications. J. Electromagn. Waves Appl. 2019, 33, 1581-1590. [CrossRef]

17. Marzouk, H.M.; Ahmed, M.I.; Shaalan, A.H.A. Novel dual-band 28/38 GHz MIMO antennas for 5G mobile applications. Prog. Electromag. Res. 2019, 93, 103-117. [CrossRef]

18. Rahayu, Y.; Hidayat, M.I. Design of $28 / 38 \mathrm{GHz}$ dual-band triangular-shaped slot microstrip antenna array for $5 \mathrm{G}$ applications. In Proceedings of the 2nd International Conference on Telematics and Future Generation networks (TAFGEN), Kuching, Malaysia, 24-26 July 2018; pp. 93-97.

19. Khan, Z.; Memon, M.H.; Rahman, S.U.; Sajjad, M.; Lin, F.; Sun, L. A Single-Fed Multiband Antenna for WLAN and 5G Applications. Sensors 2020, 20, 6332. [CrossRef] [PubMed]

20. Afzal, M.U.; Esselle, K.P.; Lalbakhsh, A. A Methodology to Design a Low-Profile Composite-Dielectric Phase-Correcting Structure. IEEE Antennas Wirel. Propag. Lett. 2018, 17, 1223-1227. [CrossRef]

21. Ray, M.K.; Mandal, K.; Nasimuddin, N.; Lalbakhsh, A.; Raad, R.; Tubbal, F. Two-Pair Slots Inserted CP Patch Antenna for Wide Axial Ratio Beamwidth. IEEE Access 2020, 8, 223316-223324. [CrossRef]

22. Balanis, C.A. Antenna Theory: Analysis and Design, 3rd ed.; Wiley: Hoboken, NJ, USA, 2005.

23. Mohamadzade, B.; Lalbakhsh, A.; Simorangkir, R.B.V.B.; Rezaee, A.; Hashmi, R.M. Mutual coupling reduction in microstrip array antenna by employing cut side patches and EBG structures. Prog. Electromagn. Res. 2020, 89, 179-187. [CrossRef]

24. Hussain, M.; Mazher, A.; Chaudary, E.; Hussain, B.; Alibakhshikenari, M.; Falcone, F.; Limiti, E. Compact Dual-Band Antenna with High Gain and Simple Geometry for 5G Cellular Communication Operating at $28 \mathrm{GHz}$ and $44 \mathrm{GHz}$. In Proceedings of the 2021 XXXIVth General Assembly and Scientific Symposium of the International Union of Radio Science (URSI GASS), Rome, Italy, 28 August-4 September 2021; pp. 1-4.

25. Altaf, A.; Iqbal, A.; Smida, A.; Smida, J.; Althuwayb, A.; Kiani, S.H.; Alibakhshikenari, M.; Falcone, F.; Limiti, E. Isolation Improvement in UWB-MIMO Antenna System Using Slotted Stub. Electronics 2020, 9, 1582. [CrossRef]

26. Withwave. Available online: www.withwave209.cafe24.com (accessed on 15 August 2021). 